\title{
The Heat Pump Systems - an Option for Energy Efficiency and Innovation of Technologies
}

\author{
Stefan P. Ditchev ${ }^{1^{*}}$ \\ ${ }^{1}$ University of Food Technologies - Plovdiv, Bulgaria \\ *E-mail of corresponding author: sditchev@gmail.com
}

\begin{abstract}
The report refers to the wider practical application of heat pumps in terms of rational use of energy resources; energy efficiency; environmental efficiency and technology innovation. Energy conservation, reduction of carbon footprint in energy production and consumption and technology innovation are global issues. The paper focuses on low potential energy sources needed to heat pumps, types of heat pumps, main guidelines and challenges when using heat pumps and the experience of experts from the Bulgarian school.
\end{abstract}

Received 8 November 2021

Accepted 10 December 2021

Published 22 December 2021

Keywords: heat pump systems, energy efficiency, refrigeration processing.

\section{Introduction}

The reduction of carbon footprint in energy production and consumption and technology innovation are global issues. In this regard in the report is presented the wider practical application of heat pumps in terms of rational use of energy resources, higher energy efficiency, environmental efficiency and technology innovation $[1,2,3]$. (NB. After the oil crisis in the Middle East in 1973 , more than 100,000 heat pump units were introduced in one year).

Heat pump (HP) is a heat machine, analogous to a refrigeration machine, in which a reverse thermodynamic cycle is performed, such as the refrigeration one, but at a higher temperature level; HP is a step-up heat converter; $\mathrm{HP}$ is a means of saving energy; HP is a means of extracting heat from low potential heat sources (LPHS); $\mathrm{HP}$ is an effective means of using waste heat.

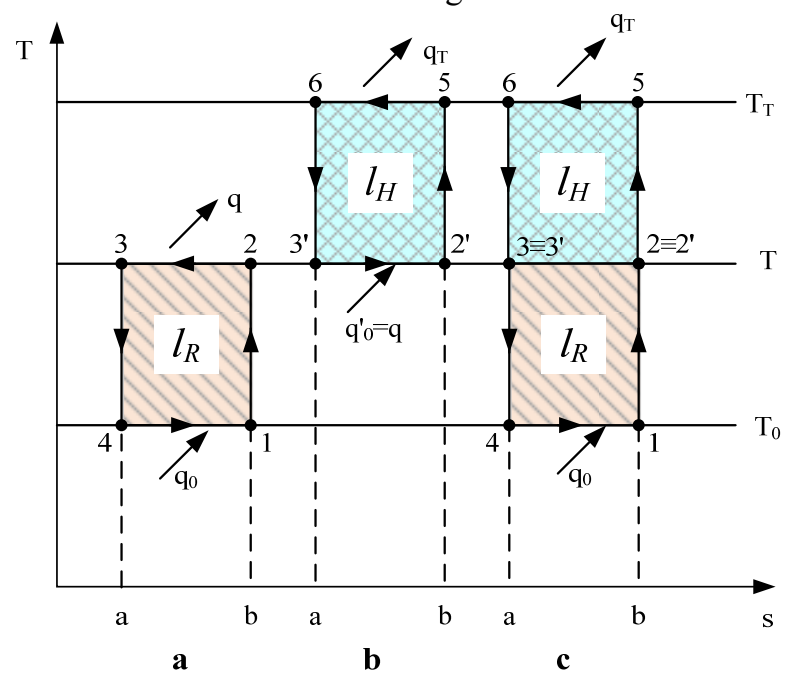

Figure 1. Reverse thermodynamic cycles.

(C) The Author(s) 2021. Published by CIEES (c) EY NC NO Association Press. This work is licensed
under a Creative Commons Attribution-NonCommercialNoDerivs 4.0 Generic License.
The reverse thermodynamic cycles are shown in Figure 1, where with $a$ is denoted refrigerant, with $b$ heat pump and with $c$ united cycle;

$\mathrm{T}_{0}, \mathrm{~T}$ and $\mathrm{T}_{\mathrm{T}}$ are respectively temperatures of cooled, ambient and heated environment, $\mathrm{K} ; \mathrm{q}_{0}^{1}$ ( $\mathrm{q}$ ), $\mathrm{q}_{\mathrm{T}}-$ respectively specific heat obtained during the refrigerant cycle and useful specific heat obtained during the heat pump cycle, $\mathrm{kJ} / \mathrm{kg} ; \mathrm{l}_{\mathrm{R}}, 1_{\mathrm{HP}}$ - respectively specific work consumed for the refrigerant cycle and for the heat pump cycle, $\mathrm{kJ} / \mathrm{kg}$

\section{Heat pump efficiency}

The efficiency of the heat pump is evaluated with the heating coefficient or coefficient of thermal transformation $-\mu$ :

$\mu=\frac{q_{T}}{l_{H P}}=\frac{T_{T}}{T_{T}-T}$,

The acceptable values are $\mu=2 \div 8$.

Technical and economic assessment for the efficiency of the heat pump is the price of the received heat, which is several times lower obtained in the traditional way.

The practical values of $\mu$ are shown on Table 1. For each HP type the value $\mu$ were measured as follow: air to air at air temperature from $-15^{\circ} \mathrm{C}$ to $7{ }^{\circ} \mathrm{C} / 35^{\circ} \mathrm{C}$; air to water at air temperature from $-15^{\circ} \mathrm{C}$ to $7{ }^{\circ} \mathrm{C}$ and water temperature $35^{\circ} \mathrm{C}$; water to air at water temperature from $7{ }^{\circ} \mathrm{C}$ to $14{ }^{\circ} \mathrm{C} / 35^{\circ} \mathrm{C}$; water to water at water temperature from $7^{0} \mathrm{C}$ to $14{ }^{\circ} \mathrm{C} / 35{ }^{\circ} \mathrm{C}$; hybrid: earth-sun at water temperature from $14{ }^{\circ} \mathrm{C} / 35^{\circ} \mathrm{C}$.

Table 1. Practical values of $\mu$.

\begin{tabular}{lccccc}
\hline $\begin{array}{l}\text { HP } \\
\text { type }\end{array}$ & air-air & air-water & water-air water-water & $\begin{array}{c}\text { hybrid: } \\
\text { earth-sun }\end{array}$ \\
\cline { 2 - 6 }$\mu$ & $1.3-4.0$ & $1.7-4.6$ & $5-8$ & $5.9-6.4$ & $3.2-3.6$ \\
\hline
\end{tabular}

Types of heat pumps

According to the number of used heat sources: Monovalent-with one low potential energy sources (LPES) $\left(\mathrm{Q}_{\mathrm{c}}=\mathrm{Q}_{\mathrm{hc}}\right)$; Bivalent - with one low potential 
energy sources (LPES) and one additional high potential heat source AHS $\left(\mathrm{Q}_{\mathrm{c}}<\mathrm{Q}_{\mathrm{hc}}\right)$ (Figure 2); Hybrid - with two low potential heat sources.

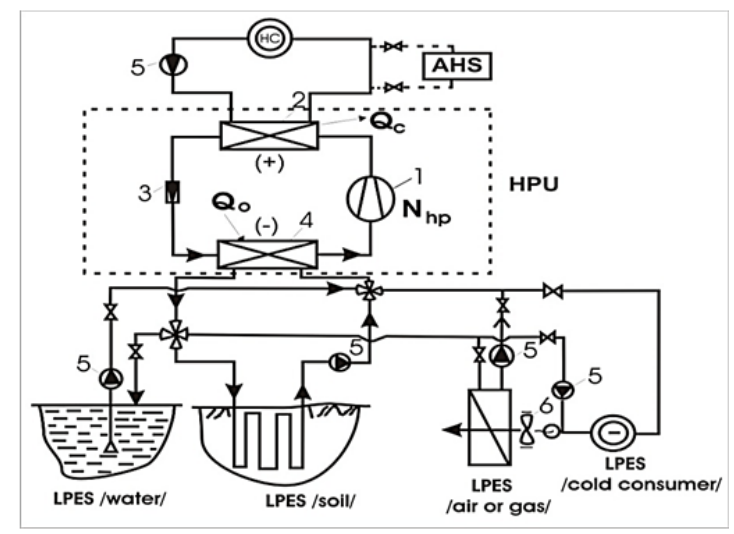

Figure 2. Bivalent heat pump system.

As shown on Figure 2, the bivalent heat pump system with low potential energy sources (LPES)-water, soil, air/gas, cold consumer and additional high potential energy sources (AHS): Qc-heat capacity of the condenser; Qhc-heat output of the condenser, HPU-heat pump unit;1- compressor; 2-condenser; 3-throttle valve; 4- evaporator; 5- pumps; 6- fan; HC-heat consumer; AHS- additional high potential heat source; $(+)$ warm side; (-) cold side of the heat pump.

According to the type of refrigerating machine: Compressor; Absorption; Ejector; Thermoelectric; Combined (Figure 3), where with 1 is denoted compressor; 2- desorber; 3-heat exchanger; 4 - pump; 5 throttle body; 6 - absorber; $Q_{\mathrm{ab}}$ - heat supplied to the absorber; $Q_{\mathrm{ds}}$ - heat received in the desorber.

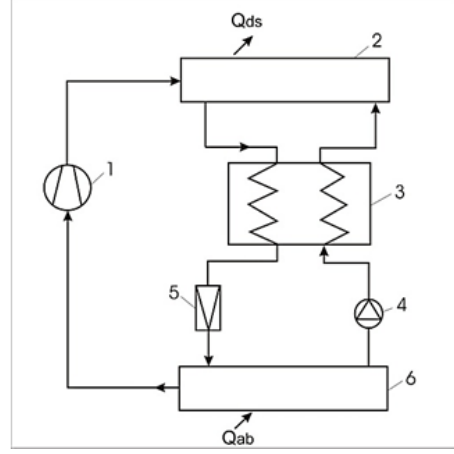

Figure 3. Example scheme of a combined compressor-sorption heat pump.

According to the method of heat transfer: Direct; Indirect-with secondary heat transfer fluid (Figure 4).

Scheme of an indirect, bivalent compressor heat pump: $\mathrm{x}-\mathrm{x}$ dividing line; $(-),(+)$ - respectively cold and warm side of HP; I- refrigerant circulation circuit; IIcirculation circuit of the intermediate fluid in the cold side; III- circulation circuit of the intermediate fluid in the warm side; 1- evaporator; 2- compressor; 3- condenser; 4- throttle valve; 5- circulating pump; 6- low potential energy sources (LPES); 7, 8-intermediate heat exchanger, respectively in circulation circuit II and III; 9- additional high potential heat source (APHS); 10- heat accumulator; 11- heat consumer; $\theta_{\mathrm{II}}$-temperature difference between
LPES (working secondary fluid in circulation circuit II) and evaporating temperature $t_{1} ; \theta_{\mathrm{III}}$ - temperature difference between condensing temperature $t_{3}$ and working secondary fluid in circulation circuit III.

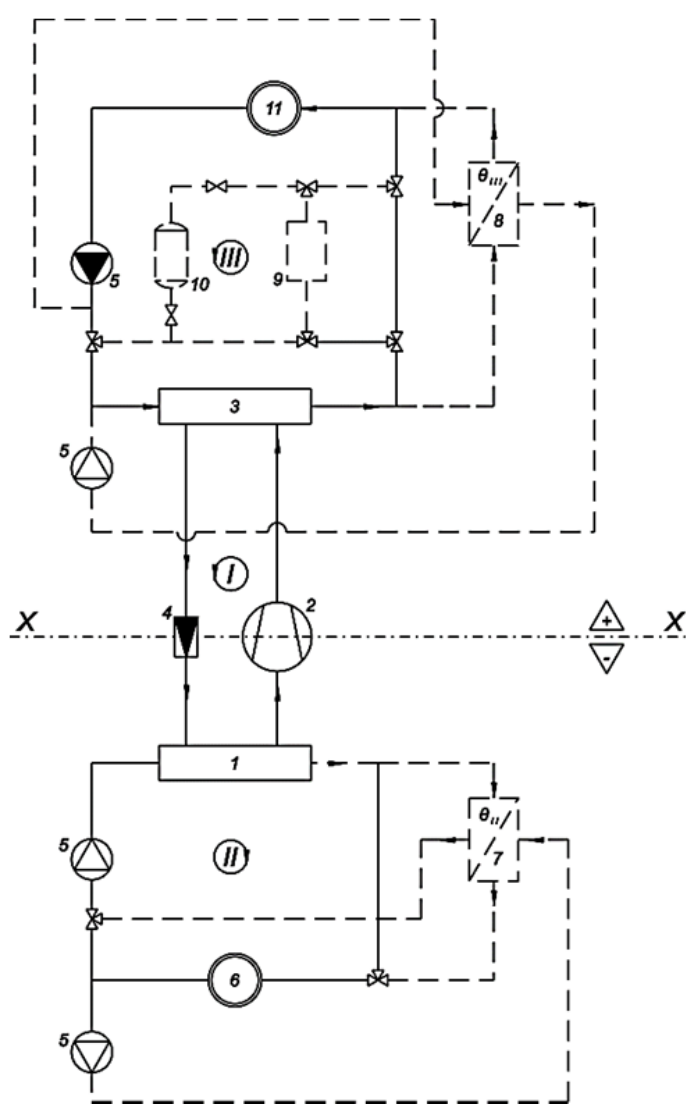

Figure 4. Scheme of an indirect, bivalent compressor heat pump.

There is another way the compressor is driven: with electric motor; with internal combustion engine. On another hand according to the physical state of the heat carrier in the hot and in the cold side: "gas - gas"; "liquid - gas"; "gas - liquid“; "liquid - liquid”.

\section{Heat sources required for heat pump operation}

There are several natural heat sources:

- Solar radiation flux - used through solar collectors and intermediate heat carrier. It is especially suitable for absorption heat pumps;

- Outdoor air - is characterized as a source with relatively low investment and operating costs and variable temperature level which is its disadvantage. Used in bivalent heat pumps for heating residential buildings;

- Soil - belongs to the low-temperature sources and has a pronounced fluctuation of temperature, depending on the daily fluctuation of air temperature, but with a pronounced attenuation in the depth of the soil layer. A depth of $0.8 \mathrm{~m}$ can be considered isothermal during a given climate season. In this case, tubular coils with intermediate heat carrier embedded in the soil are 
used, which can extract heat flux with a density of 10 to $20 \mathrm{~W} / \mathrm{m}^{2}$

- Groundwater (geothermal and artesian) - these sources have relatively high investment and average operating costs associated with drilling, excavation and installation activities.

In Bulgaria, more than 200 deposits of geothermal waters with different flow rates and temperatures have been studied. A most general and reserved assessment of geothermal resources shows that by using a heat pump when using about $100 \mathrm{MW}$ of electricity, our country can receive about $400 \mathrm{MW}$ of heat. This means that about 33 $\mathrm{t} / \mathrm{h}$ of conventional fuel could be saved in our energy economy.

- Surface water (from reservoirs, lakes, seas and rivers) - these sources are characterized by: variable temperature depending on the ambient air and relatively high operating costs associated with their delivery, protection against corrosion and pollution.

- Water from the water supply network - It is a very profitable source but is limited because can be used for low power heat pumps.

Air conditioning and ventilation; smoke; wastewater and steam from various technological processes; from refrigeration equipment at refrigeration processing and storage of food products (the temperature level at these sources of heat is from -5 to $-45^{\circ} \mathrm{C}$ ); from water cooling installations for climatic needs, etc.; from waste heat in households from wastewater. Secondary heat resources in industrial enterprise constitute up to $40 \%$ of the heat used and in households up to $20 \%$.

Use of the warm (+) and the cold (-) side of the heat pumps: for air conditioning of residential and industrial buildings; in sports facilities; in the food industry (fruit stores, refrigerators, dairy and meat processing plants, etc.); in the trade network; for technology innovation (low temperature drying of thermolabile food products, wastewater treatment, vegetable oil extraction, etc.).

The refrigerants for heat pumps, according to EU Regulation № 517 / 2014 on fluorinated greenhouse gases [7] are shown in the Table 2.

Table 2. Refrigerants for heat pumps.

\begin{tabular}{ccccc}
\hline № & Refrigerant & GWP & ODP & Composition \\
\hline $\mathbf{1}$ & R-410 A * & 2087.5 & 675.0 & $\mathrm{R}-32-50 \%, \mathrm{R} 125-50 \%$ \\
$\mathbf{2}$ & $\mathrm{R}-32$ & 675 & 0 & $\mathrm{CH}_{2} \mathrm{~F}_{2}$ \\
$\mathbf{3}$ & $\mathrm{R}-404 \mathrm{~A}$ & 0.96 & 0 & $\mathrm{R} 125 / \mathrm{R} 143 \mathrm{a} / \mathrm{R} 134 \mathrm{a}$ \\
$\mathbf{4}$ & $\mathrm{R}-134 \mathrm{a}$ & 1430 & 0 & $\mathrm{C}_{2} \mathrm{H}_{2} \mathrm{~F}_{4}$ \\
$\mathbf{5}$ & $\mathrm{R}-744$ & 1 & 0 & $\mathrm{CO}_{2}$ \\
$\mathbf{6}$ & $\begin{array}{c}\mathrm{R}-290 \\
\text { (propane) }\end{array}$ & 3 & 0 & $\mathrm{C}_{3} \mathrm{H}_{8}$ \\
$\mathbf{7}$ & $\begin{array}{c}\mathrm{R}-600 \\
\text { (butane) }\end{array}$ & 4 & 0 & $\mathrm{C}_{4} \mathrm{H}_{10}$ \\
\hline & * Will be banned after 2025. &
\end{tabular}

The main guidelines and challenges in the use of heat pumps (HP) can be summarized to:
- Maximum extraction of low potential energy sources (NPES) from the environment;

- Maximum utilization of waste heat;

- Maximum energy efficiency of HP;

- Use of indirect systems for environmental reasons [8];

- Use of refrigerants with low global warming potential (GWP) [9,10,11];

- Use of ozone-safe refrigerants with low ozone depletion potential (ODP);

- Expanding the use of natural refrigerants (air, water, $\mathrm{CO}_{2}$, ammonia, propane, butane);

- Reduction of greenhouse gas emissions and study of the life cycle of refrigerants;

- Use of energy accumulators.

They are used when the available and required energy does not match.

The efficiency of the heat pumps can be significantly improved by connecting of accumulators to both the warm and cold side of the HP.

The accumulation of energy is possible thanks to:

- the heat capacity of solid or liquid media;

- heat of phase conversion (change of physical state);

- $\quad$ chemical energy in reversible chemical reactions (change in the binding energy of molecules of two or more substances).

The main characteristics of accumulators include: reception and transmission of energy with maximum intensity, without significant temperature fluctuations; operating temperature interval, that is warm/cold inlet and outlet temperature; low discharge characteristic, that is small heat losses; homogeneity of the temperature field, that is temperature stratification; price; low energy costs for heat removal / supply / of a heat carrier or cold carrier.

Equation (2) can be used for calculation of accumulators:

$V_{a c}=a \frac{3,6 Q \tau}{C_{p} \Delta t \rho}$,

where: Vac is the volume (capacity) of the battery/accumulator/, $\mathrm{m}^{3}$; a - reserve coefficient $(\mathrm{a}=1,1$ $1,5)$; $\mathrm{Q}$-power of the condenser or evaporator, $\mathrm{kW} ; \tau$ charging time, h; c p - specific heat capacity of the liquid, $\mathrm{J} /(\mathrm{kg} . \mathrm{K}) ; \Delta \mathrm{t}$ - temperature difference, $\mathrm{K} ; \rho$ - density of the fluid, $\mathrm{kg} / \mathrm{m}^{3}$.

The following can be used for approximate calculations norms: from 0.3 to $0.4 \mathrm{~m}^{3}$ per $1 \mathrm{~kW}$ capacity of the condenser or the evaporator for daily charging $(\tau \approx$ $4 \mathrm{~h}$ ) and for night charging from 0.8 to $1.5 \mathrm{~m}^{3}$ per $1 \mathrm{~kW}$ of power.

Given that $14 \%$ of the increasing greenhouse effect is due to the refrigeration sector, due to the use of ozonedepleting chlorofluorocarbons (refrigerants), the following must be observed:

- GWP-related global environmental solutions in Montreal, Kyoto and Paris: the Montreal Protocol, the Kyoto Protocol and the Paris Protocol $[9,10,11]$; 
- EU corrective legislation to reduce refrigerant leakage from installations (EU Regulation №517/2014 on fluorine gases [7]: requirement to halve refrigerant leakage losses; the requirement to reduce by 30 to $50 \%$ the amount of refrigerant for charging refrigeration systems.

\section{The experience of the Bulgarian school}

Many factors affect the efficiency of a heat pump system. Some of them include:

- the energy consumption at the object, which must be assessed both by the consumer and by the heat source;

- the choice of scheme of the heat pump system is based on the analysis of energy consumption.

To select one or another type of heat pump it is necessary to make a technical and economic analysis of the specific conditions. Only then can be selected the specific design solution, which will ensure energy savings.

Techniques of economic evaluation are influenced by:

- thermodynamic efficiency of the heat pump system, determined by the coefficient of thermal transformation $\mu$;

- economic efficiency, is determined by the normative indicator "profitability rate expressed in \%", which is a percentage of the profit from implementation and production costs;

- feasibility study of the efficiency of the heat pump is the price of the received heat, which is significantly lower than received in the traditional way.

The first geothermal heat pump plant in Bulgaria was built in 1974 in the region of Varna and then in the resort "Druzhba" on projects and under the direction of Prof. Eng. V. Ivanov, Technical University, Sofia. In 1981 in Bulgaria in the town of Primorsko was put into operation the first heat pump installation, which uses as a lowpotential source of heat - sea water from the Black Sea.

Team from University of food technology (UFT), Plovdiv, Bulgaria [12] realized heat pump for raw dried sausages" (Figure 5).

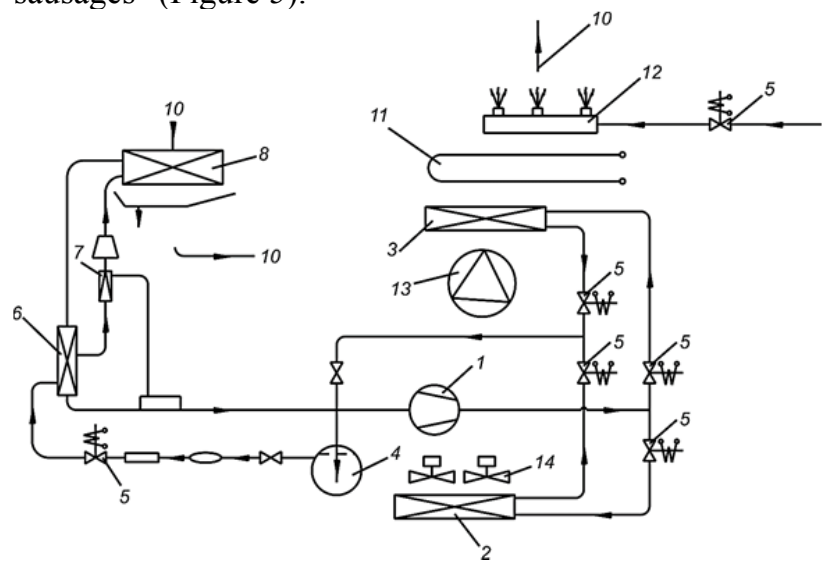

Figure 5. Heat pump for raw dried sausages: 1-compressor; 2 , 3 - respectively external and internal condenser; 4- receiver; 5solenoid valve; 6- regenerative heat exchanger; 7-thermostatic valve; 8- evaporator; 10- dryingagent (air flow); 11- electric heater; 12- humidifier; 13, 14 - respectively centrifugal and axial fan.
Advantages of this system: the current scheme replaced the existing and separate refrigeration and boiler installations in the existing air conditioning dryers in Bulgaria, which has a significant economic, energy and environmental effect in the then meat processing industry; the cold and hot sides of the heat pump are used at the same time; with its commissioning, the existing boiler plant for heat production is removed, which leads to a great energy and environmental effect.

Team from UFT, Plovdiv [13] create utility model № 1346 from 31.08 .2010 of a method and device for extraction in liquefied gases. A heat pump system for extraction of vegetable raw materials with liquid Freon R134a has been implemented (Figure.6).

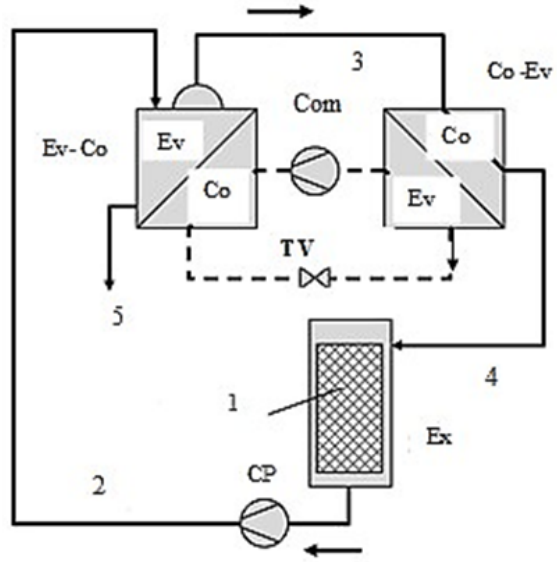

Figure 6. Heat pump extraction system: Ev- evaporator; Cocondenser; Com-compressor; TV- throttle valve; Ex- extractor;

CP-circulation pump; solvent; refrigerant;1-raw material; 2micelium; 3-vapor R 134a; 4-liquid R134a; 5-extract.

The extraction of various raw materials with liquefied tetrafluoroethane gas (R 134a) is allowed by law ("Solvent Directive" of the EU and the US FDA). The use of a heat pump system for extraction in R 134a does not affect global warming due to the tightness of the system and the complete regeneration of the solvent (R 134a). The dynamic viscosity and surface tension of $\mathrm{R} 134 \mathrm{a}$, at 200C are small - respectively $198 \mathrm{~Pa} . \mathrm{s}$ and $8 \mathrm{mN} / \mathrm{m}$, which allows its easy penetration into plant cells and deep extraction of components from them. This makes this extraction method short-lived and highly efficient. The extraction process is carried out at low pressure (from 0.2 to $0.7 \mathrm{MPa}$ ) and low / room temperature (from 20 to 350C). The extraction process has low energy costs due to the low specific boiling point of $\mathrm{R} \mathrm{134a}$ (about 200 $\mathrm{kJ} / \mathrm{kg}$ ) and the high heat coefficient of the heat pump. All this makes this method highly competitive with the existing extracts, which can be used as valuable additives for food, cosmetics and medicines., Team from UFT, Plovdiv [14] have researched in laboratory conditions (2015/2019) a mechanical vapor recompression heat pump system for wastewater treatment. The values of the coefficient of thermal transformation $\mu$ is between 3.86 and 15.42 .

Team from the Technical University-Sofia, Plovdiv branch [15] have researched of hybrid ground source heat pump system with solar collectors. A transformation coefficient $\mu=3.26$ has been achieved. 
Team from the University of Ruse, Bulgaria [16] have a patent of "Gas-Gas" Absorption Heat Pump".

\section{Conclusion and future work}

Reducing the carbon footprint of human activity, including energy production and consumption would help save the planet from global warming. They are one of the best possible options for providing the microclimate and hot water for domestic use. The high efficiency of the heat pump is proved by the fact that when consuming 1 $\mathrm{kWh}$ of electricity, they generate between $3-8 \mathrm{~kW}$ of heat. Heat pumps use electricity for their work, and if this electricity is from RES, it makes them extremely environmentally friendly and environmentally friendly.

\section{References}

[1] Ditchev S Kartelov G and Lechev D (1983) Increasing the efficiency of compressor heat pumps by obtaining multizone condensation, 16-th International Congress of Refrigeration Commission B2 Paris.

[2] Ditchev S Kalev S (1986) Rational Schemes for Application of Heat Pumps Magazine Food Industry № 6 Sofia (in Bulgarian).

[3] Rey D Makmaykl D (1982) Heat Pumps ed Energoisdat Moscow (in Russian).

[4] Eder V and others (1984) Heat Pumps ed Technique, Sofia (in Bulgarian).

[5] Ditchev S Refrigerating Machines and Installations Technique PH, 1980 Sofia (in Bulgarian).
[6] Ditchev S Refrigerating Machines Academic Publishing House of the University of Food Technologies Plovdiv 2002 (in Bulgarian).

[7] EU Regulation №517/2014 on fluorine gases.

[8] Melinder A E Granryd, 2015 IIR Handbook on Indirect Refrigeration and Heat Pump Sistems, ICR Japan.

[9] The Montreal Protocol on Substances that Deplete the Ozone Layer, 1987.

[10] The Kyoto Protocol to the UNFCCC, 1997.

[11] The Paris Agreement to the UNFCCC, 2015.

[12] Ditchev S Popov K Kartelov G Invention (AS) №77923/1987 Heat pump air dryer for raw dried sausages Sofia in Bulgarian (in Bulgarian).

[13] Nenov N Ditchev S № 1346 from 31.08.2010 Utility model „Method and Device for Extraction in Liquefied Gases, Sofia (in Bulgarian).

[14] Valchev S Nenov N 2017 Determination of specific energy consumption of mechanical vapor recompression heat pump Proc. Scientific Researches of The Union of Scientists in Bulgaria Plovdiv 14 (C - Technics and Technologies) ISSN 1311-9419 p. $99-102$.

[15] Toshkov E, Georgiev A., Popov R., and Vassileva N. (2015) Investigation methods of hybrid Ground Source Heat Pump system with solar collectors. Sixth International Conference on Energy Efficiency and Agricultural Engineering 2015, November 11-12, 2015, Ruse, Bulgaria.

[16] Iliev I., Dochev Y. and Atanasov G. Invention (AS) №50796/1995, Sofia, Bulgaria. 